SILVA, Leicy Francisca da. Filantropia e política de assistência às famílias de doentes de lepra em Goiás, 1920-1962. História, Ciências, Saúde - Manguinhos, Rio de Janeiro, v.23, n.2, abr.-jun. 2016, p.321-340.

\title{
Filantropia e política de assistência às famílias de doentes de lepra em Goiás, 1920-1962
}

\author{
Philanthropy and welfare \\ policies for the families of \\ people with leprosy in the \\ Brazilian state of Goiás, \\ 1920-1962
}

\section{Leicy Francisca da Silva}

Professora, Departamento de História/Universidade Estadual de Goiás; pesquisadora, Grupo de Pesquisa História do Cerrado Brasileiro/CNPq. Rua 35, 436 - Setor Sul

76380-000 - Goianésia - GO - Brasil

leicyfs@yahoo.com.br

\section{Resumo}

$\mathrm{O}$ artigo analisa a constituição do problema da assistência às famílias de doentes de lepra e, especialmente, aos seus filhos, no estado de Goiás, região Centro-Oeste do Brasil, no período de 1920 a 1962. Enfatiza o processo de constituição dos discursos que definem como problema a assistência médica e filantrópica aos filhos dos isolados em leprosários, e como tal processo desemboca na organização da Sociedade de Assistência ao Lázaro e Defesa Contra a Lepra, e na edificação do Preventório Afrânio de Azevedo em Goiânia, capital do estado. Esses elementos estão diretamente inseridos no processo de construção de novo quadro da história regional e de política médica e social para a lepra.

Palavras-chave: história; assistência social; lepra; Goiás; Brasil.

\section{Abstract}

This article analyzes the root causes of the shortage of social support for the relatives of people with leprosy, especially their children, in the state of Goiás, Central West region of Brazil, between 1920 and 1962. It focuses on the constitution of discourses that defined the medical and philanthropic care for the children of people isolated in leper colonies as a problem, and how this process resulted in the organization of the Society for the Welfare of Lepers and Defense Against Leprosy, and the construction of Afrânio de Azevedo children's home in Goiânia, the state capital. These elements are directly associated with the construction of a new approach in the regional history and social and medical policies for leprosy.

Keywords: history; social welfare; leprosy; Goiás; Brazil. 
Jo estado de Goiás, na região Centro-Oeste do Brasil, as famílias dos doentes de lepra momento em que a doença é popularizada como contagiosa, os doentes como sujeitos ao isolamento em instituições coloniais, e os filhos (em sentido estrito e a família em senso largo) como o mais susceptível agente de transmissão. Tal deslocamento se inicia na passagem do século XIX para o XX; no entanto, por meio dos discursos analisados, de conteúdo médico e político, podemos perceber que é posteriormente à década de 1920 que tal fenômeno recrudesce. O ápice desses procedimentos isoladores ocorre com a inauguração da Colônia Santa Marta em Goiânia, capital do estado, em abril de 1943, e do Preventório Afrânio de Azevedo no final do mesmo ano. Neste artigo interessa perceber como tais transformações se processam e como se estabelecem no cotidiano institucional os reflexos dessa prática de poder-saber.

No século XIX, dentro da concepção miasmática, o leproso é, nos discursos médicos e políticos, uma preocupação para o espaço urbano, que precisava ser purificado de todo risco de desordem. Na segunda metade desse século, o contágio era questionado pelo conhecimento médico (Andrade, 2005), e a exclusão dos doentes, como mecanismo de ação médica, era a principal ação governamental empreendida (Foucault, 1979, p.88). Esses indivíduos se agrupavam em leprosários ou optavam pela vida errante, dependendo da caridade religiosa ou particular para a manutenção de sua existência e/ou de suas famílias.

Na virada para o século XX, no entanto, ocorrem transformações referentes ao conhecimento acerca do contágio e da infecção, sendo que os interesses dos pesquisadores se situaram, a partir da constituição da microbiologia, na preocupação em relação aos modos de entrada da doença no corpo (Delaporte, 2004). A compreensão de contágio/infecção, a constituição de um novo conceito da doença (a partir das pesquisas de Amauer Hansen) e a redefinição da ideia do contágio como um risco amplo e iminente levam à reconstrução das políticas de prevenção e tratamento do doente. A novidade se apresenta na construção de um aparato profilático voltado para a proteção dos sãos, de um novo modelo institucional para isolamento dos doentes ${ }^{1}$ e de atenção aos filhos dos atingidos (Costa, 2007; Cunha, 2005; Curi, 2002; Maciel, 2007; Olinto, 2002; Monteiro, 1995). Em 1890, o Relatório da Inspetoria de Higiene do Estado de Goiás apresenta um discurso médico que expõe esse deslocamento do conhecimento sobre a doença e a imagem da família como um campo aberto para o desenvolvimento daquela "semente patológica":

Não ignorais que há no Brasil infelizmente, uma moléstia iminentemente contagiosa - a morfeia - contra a qual os recursos terapêuticos têm-se mostrado impotentes para subjugá-la. Grassando intensamente em outros estados como Minas Gerais e São Paulo, a morfeia ultimamente tem-se desenvolvido entre nós de um modo espantoso. Os indivíduos afetados dessa destruidora enfermidade têm ingresso no seio das famílias que, ou por ignorar o perigo, ou desprezá-lo, nenhuma precaução tomam para evitá-la, de sorte que essa semente patológica nenhum obstáculo encontra no seu desenvolvimento. Afastar a estes indivíduos, segregá-los da sociedade, dando-lhes porém as acomodações necessárias às suas míseras condições, eis o que a ciência aconselha para vedar-se o desenvolvimento do mal (Relatório..., jan. 1890, p.1). 
Essas transformações se materializam a partir da década de 1920, quando a Inspetoria de Profilaxia da Lepra, das Doenças Venéreas e do Câncer atuava em Goiás por intermédio da Diretoria de Saneamento Rural. As atividades afirmadas pela legislação (decreto 16.300, de 31 de dezembro de 1923, artigo 445, inciso X; e Regulamento do Departamento Nacional de Saúde Pública) consistiam na notificação compulsória e no isolamento dos doentes de lepra, na vigilância sanitária dos suspeitos, na proibição do trabalho e trânsito dos doentes, e na educação higiênica da população em geral (Santos, Faria, Menezes, 2008; Cunha, 2005). A lei indicava ainda a "assistência pecuniária aos leprosos isolados ou às suas famílias; proibição da amamentação natural pelas mulheres leprosas; ... e segregação imediata dos filhos nascidos de pais leprosos" (Silva Araújo citado em Santos, Faria, Menezes, 2008). Como se vê, as modificações concernentes ao tratamento da doença ocorrem juntamente com a construção do problema da assistência social às famílias dos enfermos (Monteiro, 1995, p.83; Santos, 2011, p.254).

Em 1925, o Regulamento do Serviço Sanitário de Goiás estabelece a necessidade de profilaxia da enfermidade, de desenvolvimento de pesquisas e a responsabilidade do Estado em oferecer condições de isolamento e de assistência ao doente (Caiado, 1927, p.15), mas nada menciona em relação às famílias. No entanto, é a partir da constituição de normas relativas à profilaxia da doença e ao isolamento de doentes que se iniciam ações em prol da construção de instituições com esse fim e, em consequência, a discussão da necessidade de assistência aos filhos dos internos. Desde 1925, ocorrem em Goiás alguns eventos que suscitam discussão nesse sentido, são eles: a constituição de uma equipe filantrópica (a Associação Caritativa Pró-lázaros) na Cidade de Goiás, então capital do estado, para a construção de um leprosário e talvez de um preventório; a edificação de três instituições filantrópicas, de origem missionária protestante; e, por fim, a divulgação de verbas federais para a construção de leprosários (na nova capital do estado, Goiânia, e na cidade de Jataí, situada na região sudoeste).

Na Cidade de Goiás, a Associação Caritativa Pró-lázaros arrecadou doações e rendas provenientes de festas e atividades diversas que foram somadas às verbas advindas de um imposto estadual sobre transporte na Estrada de Ferro Goiás e sobre a navegação fluvial (lei 812, de 28 de agosto de 1926), para a construção de um leprosário e preventório (Ofício..., 5 abr. 1932). Em 1927, após definir o plano e local de construção do estabelecimento, os representantes da Associação foram questionados por processo judicial impetrado pelos proprietários dos terrenos circunvizinhos àquele adquirido para edificação. Eles alegavam preocupação em relação à desvalorização de suas propriedades e ao perigo do contágio devido à proximidade da instituição médica. Tal arenga, que se estendeu de 1927 a 1935, teve fim favorável aos reclamantes e impediu a materialização daquele projeto filantrópico e sanitário (Autos..., 1927-1935).

Em 1935, o interventor estadual Pedro Ludovico Teixeira retoma o projeto de construção de um leprosário. Uma comissão formada por médicos e engenheiros redefine a localização do estabelecimento, situando-o no povoado de Ouro Fino, na região da Cidade de Goiás. As "condições indispensáveis" eram isolamento, existência de água potável, fácil comunicação com a capital, tamanho que permitisse a cultura agrícola e facilidade de construção (Parecer..., 1935). Em consequência, a Assembleia do Estado aprova lei que "cria um leprosário, estilo vila, 
no centro do estado" (Lei..., 10 nov. 1935), seguindo o modelo estabelecido pelo Regulamento de Saúde Pública (Goiás, 1932). Nele se especificava em relação ao leprosário, tipo colônia, que deveria contar com "enfermarias para doentes em tratamento e para a cura de afecções e doenças intercorrentes, creches, pavilhões de observações, casas para solteiros e para casados, jardins, campos de cultura, desporto e recreio" (p.93). No entanto, um desencontro das autoridades municipais e estaduais, a decisão naquele mesmo ano da transferência da capital da Cidade de Goiás para Goiânia e uma disputa entre as oligarquias no poder e aquelas destituídas impediram a implantação.

Em paralelo à tentativa frustrada da Associação Caritativa Pró-lázaros, posteriormente absorvida pelo governo estadual, de edificação do leprosário na Cidade de Goiás, três outros estabelecimentos foram construídos no estado por meio da ação filantrópica e missionárioprotestante da União Evangélica Sul-Americana. Em 1925, foi fundado o Leprosário Macaúbas na Ilha do Bananal, no extremo norte (hoje estado do Tocantins); ${ }^{2}$ em 1929, o Leprosário Helena Bernard, na cidade de Catalão, na região sudeste (na fronteira com o estado de Minas Gerais); e, em 1932, o Leprosário São Vicente de Paula, na cidade de Anápolis, na região central.

Sobre o Leprosário Helena Bernard, em Catalão, o médico Sebastião Mendonça de Brito (1946, p.53) afirma que "[s]egregou 74 doentes contagiantes e 89 enfermos e famílias receberam tratamento médico". O estabelecimento funcionava como espaço de segregação dos doentes contagiantes e como dispensário para tratamento dos atingidos por tipos não contagiantes de lepra. Ofertava aos familiares dos assistidos apoio médico, higiênico e socioassistencial como parte de seu projeto de proselitismo religioso e ensinamento de conteúdo moral, ações essas desenvolvidas, também, nos leprosários de Anápolis e ilha do Bananal. Em Anápolis, segundo o médico James Fanstone (citado em Feitosa, 2002, p.71), as enfermeiras e missionárias "gostavam de visitar e dirigir reuniões evangélicas nas cabanas de pessoas muito pobres do outro lado da cidade", assim ele decidiu adquirir naquela região um terreno onde se prestava "assistência clínica nas quartas-feiras à tarde e trabalhos evangélicos nos domingos à tarde". Eram desenvolvidas ali "quatro clínicas ... por semana; duas para leprosos e duas para os pobres" (Wilding citado em Feitosa, 2002, p.67). Esses leprosários caracterizavam-se pelo apoio tanto aos doentes quanto a suas famílias e pela característica de exclusão social, não de isolamento institucional.

Enfim, percebemos que nas primeiras três décadas do século $\mathrm{XX}$, por meio dos seus discursos e práticas, médicos, políticos e filantropos constituíam a ideia do doente como um problema sanitário, explicando a necessidade de uma política de ataque à enfermidade no estado. Era por meio da construção de enunciados problematizando tanto os doentes quanto aqueles que participavam de seu cotidiano que se poderia justificar a necessidade do chamado armamento antileprótico, que se constituía de leprosário para isolamento dos doentes, preventório para cuidado dos filhos órfãos dos pais enclausurados e dispensário para observação de novos casos. O acento sobre o risco do contágio da doença, popularizado por meio desses discursos, se fazia no processo de criação e estabelecimento do movimento sanitarista, do Serviço Nacional de Lepra e das políticas sanitárias nacionais. No entanto, em 1937, após a divulgação pelo governo federal do Plano de Ataque à Lepra e de uma lista de estados, da qual Goiás fazia parte, que receberiam verbas para a construção de leprosários, 
revigoram-se a constituição e a divulgação de discursos expondo o problema da assistência social às famílias de leprosos, dada a característica colonial e isoladora dessas instituições.

\section{Hospital colônia e preventório: a institucionalização como política de assistência}

Ao cobrarem a necessidade do leprosário e ao definirem o leproso, impondo-lhe uma imagem negativa, os médicos e políticos incrementavam o medo do contágio, a impossibilidade da cura, a exigência de um espaço apropriado para internamento e tratamento dos doentes e o abandono da família e dos amigos, reforçando o medo social. Com definição da construção do hospital colônia em Goiânia, no entanto, os discursos são redirecionados e impulsionam a discussão acerca do problema da assistência aos filhos dos internados.

Em 1937, Eliel Martins de Almeida (24 jul. 1937, p.1), filantropo e diretor do Leprosário Helena Bernard em Catalão, defendia a necessidade de adequação da profilaxia regional às recomendações da Terceira Conferência Internacional de Lepra. Nela se especificava que a ação profilática em prol da higiene pública fundava-se na identificação dos doentes e seu cadastramento, no exame bacteriológico dos suspeitos, na educação higiênica da população, no isolamento e medicação dos doentes e no internamento dos seus filhos em preventórios. Ele afirmava que se $10 \%$ dos filhos de leprosos em convivência com seus pais eram contaminados pela doença, só se chegaria ao término do problema com a construção do preventório, que ele define como sendo "o princípio de eugenia racial no domínio para o fim que se propõe". Acrescenta que as crianças eram "fontes latentes do mal", eram seres infelizes que levavam consigo "um monstro traiçoeiro" e propõe a constituição de dois tipos de preventórios: um destinado aos recém-nascidos, seguindo o modelo de creche, situado dentro dos leprosários ou em nosocômios domiciliares, já que "os menores recém-nascidos separados de seus pais imediatamente, salvam-se 99\%"; outro destinado à formação das crianças maiores, até 15 anos, à vida extrainstitucional (Almeida, 16 out. 1937, p.1). Quanto à localização, sustenta que o primeiro ficaria em Goiânia, ao lado do hospital colônia, onde se centralizaria o programa antileprótico, pois era a região do estado com maior número de doentes; o segundo em Catalão, pois "nesta cidade, dentro de pouco, será lançada a pedra fundamental do preventório, fundado e mantido pelo leprosário Helena Bernard" (Almeida, 21 out. 1937, p.4). Quanto aos aspectos da construção, insiste:

Os preventórios devem ser construídos em dois ou três pavilhões ou quantos forem necessários para abrigar os menores. Os pavilhões devem ser divididos em duas seções: masculina e feminina. Podem ser retangulares ou quadriculares, adaptados de apartamentos necessários, como: cozinha, copa, dispensa; com instalações sanitárias adequadas.

Junto aos pavilhões deve haver galpões para recreios e ao mesmo tempo adaptáveis para pequenas oficinas, como sejam: de vassouras, escovas, espanadores etc. Uma escola primária seria criada e mantida pelo governo estadual, em cada preventório. Teriam terreno suficiente para plantações de hortaliças, para o custeio dos mesmos, e para a aprendizagem da sericultura (Almeida, 21 out. 1937, p.4). 
O modelo preventorial proposto era de instituição disciplinar voltada para indivíduos sadios, mas que se não isolados, acreditavam os médicos, filantropos, políticos e demais sujeitos envolvidos naquela questão, poderiam transformar-se em fonte de contaminação.

A conveniência do preventório era justificada pelo inspetor de higiene do estado, em 1937, pela necessidade de exclusão dos filhos de leprosos das escolas. Ele apontava esse grupo, definido como "comunicantes", como suspeito de ser portador e disseminador do mal, devido à convivência com a família. Após exames no Grupo Escolar de Morrinhos, teria verificado entre as crianças 28 casos suspeitos da moléstia, diante do que reclama:

Os filhos dos leprosos, e aí está o mal maior - frequentam as escolas e são outros tantos portadores de germens que silenciosamente vão disseminando esta terrível doença entre os incautos companheiros, sendo que o mal se mostra por mais de uma vez perigoso, à vista do amplo período por que se manifesta, mormente o de incubação da moléstia que é longo e não se mostra ao primeiro exame (Silva Filho, 1937, p.49).

Na continuação desse processo, o governo do estado e a autoridade federal buscam, em 1939, entendimento com a Associação Pró-lázaros. O objetivo era a utilização da renda anteriormente arrecadada por esse grupo para construção de um preventório, no mesmo espaço em que estava sendo construído o hospital colônia Santa Marta na periferia da nova capital, Goiânia. Em uma reunião entre o médico Pedro Ludovico Teixeira (interventor por Goiás), Barros de Barreto (representante do Ministério da Saúde) e Irani Ferreira (secretário estadual de Saúde) decidiu-se que ao interventor cabia:

a instalação de dois pavilhões do 'Leprosário de Goiânia', a remoção, para este, dos leprosos da 'Ilha do Bananal', e a construção de um outro 'leprosário', no Sudoeste goiano, provavelmente, em Jataí.

O diretor do Serviço Sanitário desenvolverá esforços para que os médicos do interior, a partir de janeiro, promovam conferências, focalizando os aspectos mais interessantes da luta contra a lepra no Brasil.

O dr. Barros Barreto vai entrar, também, em entendimento com a comissão que, na antiga capital do estado, tem em seu poder certa importância destinada à construção de um preventório, a fim de que, com esse dinheiro, seja edificado, aqui, no 'Leprosário', um pavilhão, que terá o nome de 'Cidade de Goiás', como contribuição de seu povo, generoso e bom, a uma das obras de maior significação para nós, neste momento (O combate..., 27 dez. 1938, p.1).

No entanto, a tentativa não logrou êxito, haja vista que a população daquela cidade, insatisfeita naquele momento com a perda de seu estatuto de capital, decide direcionar a verba para outras três instituições sanitárias ali sediadas: o Hospital São Pedro de Alcântara, o Asilo São Vicente de Paulo e o Orfanato São José (Cidade de Goiás, 1940; Associação..., 6 jun. 1940, p.4). ${ }^{3}$

Em 1940, inspecionando as obras da nova capital do estado - Goiânia - o presidente Getúlio Vargas, em visita à cidade-leprosário, em construção desde 1937, reclamaria a necessidade de um preventório (O primeiro contato..., 8 ago. 1940, p.1-2). O isolamento do doente cobrava a indicação e promessa de assistência social aos familiares, o que exigia a instituição de aparelhos auxiliares fundamentais como escolas, granjas, institutos profissionais 
e agências sociais (Almeida, 29 out. 1938). Retomado o problema, o apoio da Federação de Assistência aos Lázaros e Defesa Contra a Lepra para a construção do preventório era a resposta: "[f]oi por isso que elementos ligados ao governo de Goiás enviaram um convite à D. Eunice Weaver, para visitar os serviços do estado e apresentar sugestões que a sua experiência do assunto autorizasse, tendo em vista nossas possibilidades locais" (Brito, ago.-set. 1946, p.53). A partir de acordo firmado com o governo estadual, a Sociedade de Assistência aos Lázaros se responsabilizava por implantar, em nome do governo do estado e interligada a sua política, o serviço de assistência aos filhos e familiares sadios de leprosos isolados na Colônia Santa Marta (Resumo..., 20 dez. 1941, p.2-3).

Dessa memorável visita resultaram a fundação de um órgão subordinado à Instituição que dirigia, bem como os planos para a criação do que é, em nossos dias, o Educandário Afrânio Azevedo. Esse Educandário, que abriga grande número de crianças, filhas de pais recolhidos na Colônia de Santa Marta, é dirigido pela incansável senhora dna. Yone de Freitas (Brito, ago.-set. 1946, p.53).

Em 1941, em conferência proferida no Automóvel Clube, o executivo local e a benemérita e presidente da Federação das Sociedades de Assistência aos Lázaros e Defesa Contra a Lepra, Eunice Weaver, expõem os dados sobre "a aparelhagem" com a qual contavam "para extinguir essa enfermidade, os meios de evitar o contágio e de impedir que os filhos de lázaros adquiram dos pais a repelente moléstia" (Iniciada..., 29 nov. 1941, p.1). Em suas falas, propõem a criação de um preventório em Goiânia e divulgam a criação de comissões (formadas pelas senhoras da sociedade local) e da campanha para arrecadação de contribuições para a obra. O objetivo era arrecadar o valor de "seiscentos contos de réis"; o estado já teria destinado 150 e o governo federal cinquenta, para obtenção do restante "realizar-se-ão diversas festas nesta capital, a partir de hoje, com uma ceia, no Automóvel Clube" (Iniciada..., 29 nov. 1941, p.1).

A Comissão Executiva Pró-Construção do Preventório Para Filhos de Lázaros lança o Edital de Concorrência Pública com exigências específicas, segundo o plano de edificação do chamado armamento antileprótico - leprosário, preventório e dispensário (Concorrência pública..., 6 dez. 1941, p.3). A construção deu-se em um período consideravelmente curto, com a ampla participação popular e inspecionada pela presidente da Federação, Eunice Weaver (Nesta capital..., 16 jun. 1943). Em sua estadia na capital, ela incentivou a fundação de afiliadas nas principais cidades do estado (Trecho..., 9 jun. 1943); elegendo para a direção nomes de pessoas influentes, o que facilitava os trâmites para arrecadação de donativos. Na antiga capital, por exemplo, "para encetar a campanha da Semana Pró-Preventório" elegeu-se para a direção do estabelecimento a professora Maria H. Péclat, conhecida da população; em Goiânia, na indicação de sua presidência de honra o nome do interventor e sua esposa, e do quadro de membros os principais representantes da política ludoviquista (Resumo..., 20 dez. 1941, p.2). A participação popular foi incontestável, a definição do nome do estabelecimento considerou o principal doador, Afrânio de Azevedo, um capitalista do Triângulo Mineiro (Costa, 28 set. 1943). Como explica Luciano Curi (2002, p.120), os políticos eram os primeiros participantes das campanhas de arrecadação de verbas.

A construção das associações da Sociedade de Assistência aos Lázaros e Defesa Contra a Lepra coloca a assistência aos leprosos diretamente ligada ao projeto de unidade nacional do 
governo Vargas (Santos, 2006) e por reflexo ao governo estadual de Pedro Ludovico Teixeira. A implantação, em Goiás, da Sociedade de Assistência aos Lázaros e Defesa contra a Lepra ocorre em 1941, embora o Boletim da Sociedade informe a filiação de uma representação na cidade goiana de São Simão em 1932 (citado em Santos, 2011, p.258) e Souza Araújo (1937, p.154) afirme que desde 1936 a Federação "começou a agitar o problema".

Após 1943, a Sociedade assume a assistência aos lázaros e suas famílias, repetindo o que se passava em nível nacional (Resumo..., 20 dez. 1941) desde a década de 1920. Anteriormente, as ações filantrópicas eram desenvolvidas por instituições ligadas à ação religiosa protestante e, como no resto do país, dependiam da doação de indivíduos pertencentes às classes abastadas (Sanglard, 2005), da ação de grupos cujo interesse era a manutenção ou defesa da ordem e da civilização (Olinto, 2002), ou da participação da classe média interessada em estabelecer localmente o modelo higiênico observado alhures (Alvarenga, 2011). Nos diversos estados, as instituições preventoras foram construídas pela Federação e mantidas com o apoio de subsídios públicos em todas as esferas (federal, estadual e municipal) e com intensa participação da população.

Os discursos de valorização do trabalho das sociedades expunham que o preventório para os filhos dos leprosos era a única via plausível em decorrência do preconceito e medo com que os impregnava a suspeita de ser um portador do mal. A promessa era de que, no preventório e longe do inexplicado repúdio, aquela criança teria assistência médica, frequentaria escola técnico-profissional e seria educada (O problema..., 29 out. 1939). A sociedade repudiava os entes sadios advindos de lares onde havia leprosos. Nas escolas públicas se proibia a entrada de crianças advindas de famílias ou que convivessem com indivíduos portadores de males infectocontagiosos, o que justificava a publicação dos seguintes questionamentos:

Como proteger as mulheres e demais dependentes do infeliz que, repentinamente, fora afastado do lar? Como salvar de um cruel destino as crianças que tiveram a desdita de serem filhos de leprosos? Como prover a manutenção da família as mães sadias, que havendo perdido os seus companheiros, ficaram acorrentadas aos deveres que lhes impõem os filhos pequeninos? Ademais, a família dos leprosos, mesmo sadia, não é julgada como tal e, assim, se vê obrigada a viver no meio da população que a evita e a repudia (Brito, 1946, p.53).

Seguindo uma regra nacional, o trabalho desenvolvido pelas entidades públicas ou privadas foi relacionado com a tarefa de salvação da raça, impedida de progredir diante do grande número de doenças, posição exposta na chamada pública de lançamento das obras. Aos preventórios se relacionava ainda o desenvolvimento da civilização (pela formação moral e religiosa dos doentes e seus filhos) e a eugenia (pelo impedimento do risco de contágio em relação à população sadia). A construção dessas sociedades auxiliares criava uma rede de poder em relação à doença e aos doentes, ao mesmo tempo que tornava mais humana a política antileprótica, promovendo "além da construção desses estabelecimentos de preservação da raça brasileira [Preventórios], a construção de capelas e pavilhões de diversões para os enfermos recolhidos nos leprosários" (O problema..., 29 out. 1939, p.1).

O apoio cultural, moral, espiritual e de lazer servia como argumento em prol da melhor adaptação dos doentes nos espaços coloniais e à condição de isolado. No leprosário, a sociedade 
oferecia opções para ocupação do tempo vazio, impedindo os internos de pensar na condição em que estavam internados e, no quadro geral, em que estavam inseridos. Ofertando o amparo social às famílias e especialmente aos filhos internados em preventórios, se constituía sobre os leprosos uma dupla vigilância e controle. Compunham-se as estratégias para impedir a subversão, todas parte de um plano humanitário e religioso, advindas de políticas públicas e direcionadas a grupos de famílias das classes populares (Danzelot, 1986).

À "assistência moral e espiritual aos hansenianos isolados em nosocômios, junta-se o amparo moral e econômico à família de enfermos necessitados, levando assim essas associações beneméritas tranquilidade àqueles que por amor da sociedade sadia foram obrigados a isolarse" (O problema..., 29 out. 1939, p.1). O escopo da Associação de Assistência aos Lázaros estava diretamente ligado às atividades de lazer e educação nas colônias; ao amparo às famílias de doentes; à preservação da prole sadia dos enfermos; à assistência aos egressos dos leprosários e à cooperação com a saúde pública na propaganda contra a lepra (O problema..., 29 out. 1939). A função social e política dessas instituições estava posta, daí o porquê da importância que elas tiveram durante o período estudado, recebendo status idêntico ao de alguns órgãos públicos e dando visibilidade aos dirigentes desses órgãos - Alice Tibiriçá e Eunice Weaver.

A preocupação com o problema da lepra, dos leprosos e dos seus familiares toma grandes proporções com a participação de grande parte da comunidade e expõe o nível de envolvimento emocional que aquela campanha alardeava. Essa participação era fruto de chamados, expostos em grandes letras nas primeiras páginas dos jornais, convidando o povo a "livrar o Brasil do flagelo da lepra". Para alcançar tal objetivo, "é preciso que todos ajudem no limite de suas possibilidades. Neste momento o governo e o povo goianos estão empenhados nessa grandiosa campanha de solidariedade humana" (Iniciativa..., 27 nov. 1941, p.1). Dentre as diversas propostas de apoio social à causa, a sugestão de Genezi de Castro Silva, para criação de um novo imposto a ser pago pelos pais de crianças sadias menores de dez anos, mostra como o problema da lepra se expande e passa a fazer parte das discussões constantes na vida privada, além daquelas já propostas pelo espaço público. Ela aconselha que a verba arrecadada fosse encaminhada para os filhos de leprosos e que, junto ao documento de cobrança, os pais recebessem o seguinte apelo: "Vosso filho, que é são, alegre e feliz, vai contribuir pagando esta pequena multa, para que os seus companheiros, filhos de leprosos, possam ser também felizes na infância, fortes na mocidade e úteis na adolescência" (Iniciativa..., 27 nov. 1941, p.1).

Inaugurada a Colônia Santa Marta em abril de 1943, a urgência na finalização das obras do preventório se faz sentir, pois como ficariam os filhos sadios dos doentes isolados? A resposta para esse problema vinha na busca de verbas adicionais; divulgava-se, então, a festa da caridade, uma festa dançante "promovida por damas da mais grada situação na sociedade desta capital" no Lago das Rosas, em Goiânia (Festa..., 17 set. 1943, p.1). Os discursos cobravam a necessidade emergente da inauguração daquela instituição, pois na colônia setenta crianças aguardavam para ser encaminhadas ao preventório, "filhas de leprosos, todas elas com reação positiva de Mitsuda" (Costa, 28 set. 1943, p.1, 4). ${ }^{4}$ 


\section{Disciplina e cotidiano medicalizado no Preventório Afrânio de Azevedo}

Com o início dos trabalhos, era por meio da organização de festas que se arrecadavam os valores para custeio do estabelecimento (Natal..., 3 dez. 1943), já que após a construção, segundo o Plano Nacional de Combate à Lepra, as filiadas da Federação de Assistência aos Lázaros e Defesa Contra a Lepra eram responsabilizadas pela sua administração e manutenção. Por isso, a necessidade do reforço de "um trabalho verdadeiramente filantrópico", bem como do "carinho e o zelo dispensados à criança nascida de pais leprosos - um exemplo de trabalho e organização" (O Educandário..., 1944, p.463). De outro lado, ainda, reforçava-se a incapacidade dos pais e familiares de custear a manutenção das "pobres crianças que nele estão abrigadas" (p.463).

No preventório, respeitando-se o regulamento, organizaram-se as condições para a produção interna de víveres, com a doação de uma extensa área, com quarenta hectares e "35 ares (sic)" de terras cultiváveis, situada nas suas proximidades, onde, em 1947, foi construído um novo dormitório e um aviário. As atividades produtivas objetivavam a formação educacional dos internos e a diminuição de gastos para manutenção do estabelecimento (Decreto-lei..., 4 nov. 1943; Edital..., 20 set. 1947). Desenvolvia-se ali o processo de assistência, disciplinamento e cuidado de recém-nascidos, crianças e adolescentes sadios; um conjunto formado por vítimas das políticas públicas antilepróticas, separadas de suas famílias para se evitar o risco do tão temido contágio (Guimarães, Cruz, 2002).

O regulamento produzido pela Federação das Sociedades, e aprovado pelo Departamento Nacional de Saúde, previa normas concernentes às regras de ensino, à economia interna e ao disciplinamento dos alunos, e expunha uma forma de automanutenção por meio do trabalho dos internos (Regulamento..., 1 mar. 1944, p.7-8). ${ }^{5}$ Definia que os preventórios eram destinados a "acolher, manter, educar, instruir os menores sadios, filhos e conviventes de doentes de lepra, desde que não tenham parentes idôneos que queiram assumir esse encargo e que disponham de recursos para educá-los e mantê-los sob a vigilância das autoridades sanitárias competentes" (p.7-8). A instituição acreditava que, para cumprir sua finalidade, era preciso que os internados permanecessem no preventório no mínimo seis anos, até o limite de 15 anos de idade para os meninos e 18 para as meninas (Regulamento..., 1 mar. 1944). Seu corpo técnico era formado por médico, dentista, enfermeiro, nutricionista, educador e agrônomo ou capataz rural. Ao agrônomo ou capataz competia "dar instruções práticas de campo a todos os internados em idade adequada e de acordo com as indicações médicas, compreendendo essa instrução o maior número de atividades, tais como pequena agricultura, fruticultura, jardinagem, horticultura, criação em geral etc." (p.7-8). Combinando ainda com o objetivo de produção interna, o ensino no preventório cumpria os seguintes cursos: jardim de infância; primário, de acordo com o programa oficial; escolas domésticas em todas as suas múltiplas atividades; pequena lavoura e trabalhos de campo; artes e ofícios. A partir dos 12 anos, os internos prestavam "pequenos serviços ao Preventório, a título de aprendizagem, uma vez julgados aptos a fazê-lo, sendo aproveitado o pendor natural que manifestarem por esta ou aquela atividade" (p.7-8). No entanto, só poderiam ser remunerados quando tivessem mais que 
16 anos, com um valor relativo a 30\% do salário pago a empregado em trabalho idêntico (Regulamento..., 1 mar. 1944).

O isolamento dos internos naquela instituição, definida como sendo um "estabelecimento hospitalar ou de assistência social" criado "ao serviço da sociedade e da própria civilização", voltado exclusivamente para o cuidado de crianças sãs, era notado, ainda, no seu distanciamento da povoação; situava-se em uma "colina afastada do centro da cidade, lá bem longe, perto do bairro de Campinas" (O Educandário..., 1944, p.463). Aquele espaço reforçava ainda mais o afastamento dos seus internos dos familiares, pois estava geograficamente instalado, na capital, em ponto oposto à colônia Santa Marta. No cotidiano, "acolher, manter, educar e instruir" se traduzia em normas e atividades pontuadas pelo relógio e impostas àquelas duzentas crianças, que segundo a Revista Oeste, povoavam o estabelecimento em janeiro de 1944 . O viver estava circunscrito aos muros institucionais. A escola frequentada por eles, o Educandário Eunice Weaver, foi construída anexa ao estabelecimento (decreto n.12 do governo estadual, abril de 1944). Como expõe Lima (2011, p.94), uma experiência de segregação "resultante e resultado de outra forma de isolamento", aquela do sistema colonial dos leprosários. Todas as crianças se disciplinavam a uma rotina, pontuada por um "regime especial". Mesmo sãs, as crianças se situavam dentro da lógica da política de proteção contra a lepra e das ações isolacionistas, vivenciavam um espaço e um tempo regulamentados (Foucault, 2004).

Todas elas têm um regime especial. Levantam-se cedinho, tomam o café, vão à escola, brincam, almoçam, passeiam pelos bosques próximos, trabalham, descansam, jantam, ouvem histórias de príncipes e rainhas e, afinal, antes das 20 horas, dormem sossegadas, após um dia intenso de atividade. Eis um pequeno resumo da vida interna do Educandário 'Afrânio de Azevedo' (O Educandário..., 1944, p.463).

As crianças ficavam sob a responsabilidade médica de Maria de Lourdes Morais e Mário Purri, leprólogo e diretor da colônia, também responsáveis pela definição da dieta. A reorganização dos hábitos, a definição e o controle do tempo gasto em atividades específicas, a docilização e a dominação do corpo eram estratégias cotidianas naquele processo de disciplinamento elaborado pelo poder saber médico (Foucault, 1979). O choque do afastamento da família, do isolamento em relação à cidade, e da reelaboração do cotidiano e dos hábitos era abrandado pelo desvelo dos cuidadores; na direção, estava dona Yone, a quem a população da cidade já havia se acostumado "a ver ... correndo à pressa, trabalhando pelo Educandário, fazendo compras, pedindo donativos, promovendo festivais, solicitando tudo enfim que seja para o benefício das criancinhas que ali vivem sob o cuidado de mulheres dedicadas" (O Educandário..., 1944, p.463).

Os discursos médicos e políticos no mesmo exercício de construção da lepra e do leproso formaram os espaços de exclusão que, nessa operação, não se restringiram apenas aos doentes. No momento em que se alargam os mecanismos de proteção contra a lepra, com os leprosários - para isolamento dos doentes -, os dispensários - controlando o risco do contágio dos comunicantes - e os preventórios - para assistência médica e social aos filhos menores saudáveis dos doentes isolados -, abrange-se uma larga população sadia dentro de um discurso do patológico. O cotidiano da instituição se alinhava e estava intimamente ligado ao que o ritmo das políticas contra a lepra definia. Acrescente-se o temor que rondava as crianças 
internas regularmente examinadas por profissionais, sofrendo o medo constante de obtenção da enfermidade e, mais tarde, a subordinação de seus corpos a tratamentos e a pesquisas diretamente relacionadas ao risco de contágio da doença. Justificando sua pesquisa acerca da profilaxia com o BCG em crianças internas de preventórios, o médico Nelson de Souza Campos (1953, p.11) afirma: "Esta questão de patologia geral se aplica a todas as enfermidades infecciosas, e a lepra não pode fugir à regra geral. Sabemos de organismos imunes a ela, como sabemos de organismos predispostos a ela. Dos indivíduos passamos para a família, da família à coletividade e da coletividade aos povos".

Os trabalhos de pesquisa e ensaio da vacinação com o BCG entre os filhos saudáveis de pais leprosos, entre os anos de 1947 e 1952, desenvolvidos por Nelson Souza Campos, inserem-se na lógica da profilaxia coletiva. Em 1953, o médico publicou os resultados de suas pesquisas com um quadro identificando 34 internos do Preventório Afrânio de Azevedo em Goiânia com idade entre 4 e 20 anos. Elas haviam recebido no período doses do BCG como método profilático contra a lepra. O que as fazia pioneiras na experimentação daquela prática profilática era a identificação com um problema médico-social: o grau de parentesco e o tempo de convívio com leprosos.

É por meio dos anexos da pesquisa que podemos identificar Ozini, o primeiro da lista apresentada pelo médico. Sua experiência expõe a constante observação a que os corpos dessas crianças estavam submetidos e como seu cotidiano era medicalizado e perscrutado pelo fantasma do medo da obtenção da lepra. Com idade de 13 anos e tendo convivido por 3 anos com a mãe doente, ele se submeteu, entre 1949 e 1951, a seis exames de Mitsuda anteriores ao recebimento de três doses de BCG e, para posterior avaliação da sua reação àquele tratamento preventivo, sujeitou-se a mais três exames de Mitsuda. ${ }^{6}$

Outro caso era o de Heleny. Cruzando informações, podemos pressupor ter nascido em leprosário. Com idade de 7 anos quando da publicação da pesquisa, não indicava convívio com pai ou mãe doentes. Ela foi submetida a seis exames de Mitsuda anteriores ao recebimento de três doses da vacina BCG e a três novos exames posteriores à vacinação. ${ }^{7}$ Os estudos acerca da leprominorreação se deviam à análise da relação entre lepra e tuberculose. Esse conjunto de crianças sujeitadas aos experimentos apresentava resultados negativos de Mitsuda que, após o uso oral do BCG, foram positivados. Acreditava-se na capacidade da vacina com o BCG imunizar organismo contra a doença; a positivação dos testes de Mitsuda era o sinal confirmativo dessa experiência. Tal resultado, segundo a pesquisa, indicava o valor profilático daquela prática contra o contágio da enfermidade (Campos, 1953).

Se no começo da década de 1950 o disciplinamento e a medicalização do estabelecimento estão claros nos documentos analisados, na passagem para a década de 1960 outros obstáculos relativos à manutenção, ao disciplinamento e à condição higiênica expressam-se no trabalho dos internos, nas fugas e nas reclamações sobre maus-tratos. O debate entre vereadores na Câmara Municipal de Goiânia e o posicionamento público do preventório sobre esse problema em fins da década de 1950 expõem a dificuldade financeira de manutenção daquele aparelhamento sociomédico. O discurso proferido pelo vereador de Goiânia Felisberto Braga, em 1959, denuncia maus-tratos, falta de material de higiene para as crianças, fugas, descaso em relação ao atendimento médico e má administração (Braga, Neto, 15 maio 1959, p.8). Ele "criticou com veemência a atuação da diretoria" considerando "verdadeiramente 
lastimável a condição de higiene em que se encontram as crianças internas" (p.8). Durante sua visita à instituição, teria perguntado sobre duas crianças internas.

A resposta obtida foi de que haviam morrido. Nessa altura o orador interrogou: 'morre como, sr. presidente?' - em tom alarmado, para depois acrescentar que o 'médico não comparece ali para examinar as crianças, passa mais de seis meses sem fazer uma visita' ao Educandário. 'Dá receita pelo telefone' - asseverou (Braga, Neto, 15 maio 1959, p.8).

O vereador Elias Neto reafirma essas denúncias e pede abertura de inquérito para investigação das responsabilidades relativas àquela situação. Ele especifica em relação à higiene do espaço: "no Preventório, existe um quadrado de uns oito metros por oito, o qual é chamado de 'chiqueirão', onde são deixadas crianças nuas sobre o cimento frio. Em completa promiscuidade, as crianças ali ficam e fazem suas necessidades" (Braga, Neto, 15 maio 1959, p.8).

Na continuidade daquele debate, Hely Mesquita, Nion Albernaz e Tabajara Póvoa, vereadores participantes da comissão de análise do estabelecimento, afirmam que haviam constatado "uma preocupação da Diretoria e dos funcionários em fazerem uma boa administração" e cobram respostas do Executivo às reivindicações da instituição. A defesa do estabelecimento se faz justificando que o problema existia, mas que não era específico daquela instituição, pois "em comparação com o 'inferno' dos tuberculosos existentes às margens da estrada que demanda ao aeroporto", 8 o preventório era "um paraíso" (Declaração..., 18 maio 1959, p.2; destaque no original).

Por parte da administração, a resposta àquelas críticas dava-se no sentido de reafirmar o seu trabalho na formação moral, religiosa e na assistência médica e social aos internos; um trabalho desenvolvido, naquele período, por um grupo que contava, na assistência médica, com os doutores Joaquim Neto Carneiro Filho (residente) e Martiniano Rossi do Serviço Nacional de Lepra, e, na assistência religiosa, com o padre Serra e as irmãs dominicanas. Não sendo remunerada, contava com o apoio da população, e não com "acusação, muitas vezes leviana e apressada e que não representa a realidade, fruto, talvez, de apreciação unilateral, além de constituir um desestímulo para quem trabalha" (Carta enviada..., 18 maio 1959). A instituição vivia um momento de crise que atingia fortemente seu cotidiano e que se expressava nas fugas, na má assistência prestada aos internos e na exigência do seu trabalho para diminuição das despesas. Mas, como afirmariam os vereadores que compunham a Comissão de Investigação sobre as condições do estabelecimento, ao menos "ali realmente se faz alguma coisa para os "órfãos de pais vivos'” (Declaração..., 18 maio 1959, p.2), uma população considerável que passou dos setenta quando de sua inauguração para 190 em 1956 segundo dados do Censo da Lepra (IBGE, s.d.).

A assistência social das famílias passa, a partir de determinado momento no estado de Goiás, a fazer parte da reclamação advinda dos doentes internados. Em carta expedida ao prefeito, um ex-funcionário da prefeitura da Cidade de Goiás, isolado na Colônia Santa Marta, exortava sua "caridade cristã" para com a sua situação. No entanto, era o reconhecimento da assistência como justiça, segundo o reconhecimento das "diretrizes do Direito", que reclamava (Ofício..., 14 set. 1953): 
num período de 3 anos trabalhei como limpador de rua, nessa prefeitura, serviço braçal, conforme v. excia. poder-se-à verificar através dos arquivos nas Folhas de Pagamentos. Estou internado nesta colônia desde dezembro do ano de 1944, por ser acometido pelo mal de Hansen, sem possibilidade financeira, isto porque, senhor prefeito, até a presente data, nunca acreditei ser possível conseguir uma pequena gratificação, mesmo aureolado de direito, graças aos meus serviços prestados, conforme acima foi enumerado. Atualmente, deparando diversos casos idênticos ao meu, aos quais foram concedidas remunerações dentro do ditame da verba de 'assistência social', rogo-lhe, veementemente, os meus inestimáveis préstimos no sentido de que me seja concedida uma pequena remuneração, dentro das possibilidades deste município, optando pela verba em consideração.

Tal conteúdo discursivo mostra o reconhecimento dos direitos por parte daqueles que foram convidados a se isolar em prol da saúde pública e impõe o seguinte ques-tionamento: esses valores, no caso de decisão favorável, seriam encaminhados ao pagamento de seus gastos pessoais ou ao sustento de sua família? Qualquer uma das respostas, no entanto, está situada no quadro da carência material dos atingidos direta ou indiretamente pela doença.

O sucesso relativo ao uso da nova medicação e o fracasso que se mostrava quanto aos resultados do modelo isolacionista, bem como a crise financeira que atingia os órgãos ligados à política antileprótica, indicavam o reposicionamento no modelo profilático afirmado em 1956 numa Declaração de Princípios dos Leprólogos Brasileiros. Em 1958, no Sétimo Congresso Internacional de Lepra ocorrido em Tóquio, se firma a priorização do uso dos medicamentos para tratamento dos doentes e o fim do isolamento como política (Opromolla, 2007, p.69). Após 1958, com as modificações do Programa de Profilaxia da Lepra, mesmo com a manutenção das instituições (leprosário, preventório e dispensário), há alterações quanto à sua função. O preventório perdia o papel profilático, não se justificava sua necessidade quando se afirmava a permanência dos doentes em suas residências e a manutenção da estrutura familiar, com o tratamento à base de sulfonas (Pereira, 1960, p.9). Assim, para justificar a continuação do preventório, reforçava-se o seu papel de educação e de formação sanitária (Curi, 2006), o que se contrapunha fortemente com a imagem divulgada por meio das denúncias.

No início da década de 1960, na busca de verbas públicas locais destinadas à assistência social, a direção do estabelecimento tenta suprir as carências advindas da crise que se abate sobre o Programa de Profilaxia da Lepra. Ao governador Mauro Borges era cobrado, em 1962, durante visita àquela instituição, que reconhecesse as "dificuldades que enfrenta a direção do estabelecimento" e tomasse as "providências ao alcance de sua administração a fim de dar um auxílio ao Preventório". Após sua visita, para "se inteirar de suas dificuldades atuais e de seu funcionamento", o governador "prometeu enviar a São Paulo uma criança que ali se encontra e que nasceu com deficiência dos membros inferior e superior direito, a fim de que ela se submeta a tratamento especial no Departamento Ortopédico do Hospital das Clínicas, da Paulicéia" (Mauro Borges..., 11 set. 1962, p.6). Quanto ao custeio das atividades cotidianas, nada foi acrescentado. Em suma, a partir de então, escasseava-se a intervenção financeira pública naquela instituição, era preciso apelar para a caridade privada, o que as mães hansenianas fizeram no Natal de 1962, pedindo doação para os seus filhos. Por meio de seu agradecimento, insistiam: 


\begin{abstract}
Não só de Goiânia, como de muitas partes do estado, nossos filhos receberam dádivas valiosas. Esperamos continueis a favorecê-los com vossa bondade; não vos esqueçais de que eles necessitam constantemente de vossa ajuda: os brinquedos velhos, as roupinhas usadas, os excessos de vossas mesas remeitei-os ao Educandário Afrânio de Azevêdo, para a alegria dos que lá vivem e que dependem também de vossa generosidade (Mães hansenianas..., 23 jan. 1963).
\end{abstract}

A análise das entrevistas citadas por Guimarães e Cruz (2002) nos permite acrescentar que no preventório a vida das crianças internas segue o mesmo ritmo e se subordina ao mesmo preconceito dos pais no leprosário Colônia Santa Marta. Assim como os pais, precisam se adaptar à vida do trabalho institucional; o que diferenciava era que se tratava de trabalho infantil, justificado pela imagem de atividade de aprendizado e formação.

\title{
Considerações finais
}

A legislação brasileira referente à assistência social das famílias cobria o cuidado de crianças dentro dos leprosários, construindo para tanto creches e orfanatos nas colônias de leprosos. Para os filhos sadios, o auxílio constituía-se na sua separação da família logo ao nascer e amparo relativo aos aspectos básicos de sobrevivência mantidos pela Sociedade de Assistência aos Lázaros e Defesa Contra a Lepra. Na Conferência de Assistência Social aos Lázaros (2 jul. 1945), um grupo de trabalho desenvolveu estudos sobre a assistência aos lázaros como dever social (Santos, 2011, p.269). A lei n.610 definia, desde 1949, a assistência às famílias dos isolados (Diniz, 1951). Ela estabelecia que a assistência social se faria em relação aos doentes não isolados por meio do seu reajustamento ocupacional; para as crianças sadias, filhos de leprosos isolados, por meio de sua realocação em novos lares ou em preventórios; para os isolados, com apoio jurídico para resguardo dos interesses patrimoniais e familiares (Brasil, 13 jan. 1949).

A abrangência da legislação, no entanto, não satisfazia às necessidades reais, levando, em 1951, à reclamação de Ernani Agrícola (1951) sobre a situação social dos isolados, das suas famílias e dos transferidos para dispensários no Brasil. Diante do quadro social brasileiro, outro médico envolvido na campanha de profilaxia da doença questionava:

De um modo geral, a grande maioria dos leprosos vem do interior dos nossos estados, onde ... o chefe da família é quem tudo resolve, é quem tudo sabe.

Pois bem, imaginai uma casa pobre onde o chefe fique doente de lepra e seja levado para uma colônia; levai o vosso pensamento mais adiante e imaginai esse enfermo louco ou sentenciado; pesai bem agora as consequências da retirada deste homem daquela casa pobre; a miséria que lá rondava de perto a casa, ali penetrará e fixará residência; quem dará o pão à mulher e aos filhos do pobre hanseniano? Quem lhe dará conselhos nas horas aflitas? É desumano deixá-los assim abandonados à própria sorte (Rezende, 1941, p.30-31).

As condições sociais, tanto dos doentes quanto de seus familiares, levavam grupos envolvidos com a causa humanitária a buscar outras soluções possíveis para o problema. Na cidade de Jataí, por exemplo, diante da incapacidade financeira do estado de construir ali o leprosário anteriormente prometido, a população teria constituído, nas décadas de 1940 a 1960, um 
bairro para os doentes e suas famílias. Em decorrência do desenvolvimento econômico, muitos imigrantes eram atraídos para a cidade; entre eles, alguns leprosos em busca de caridade. A solução foi construir "fora do perímetro urbano" um conjunto de residências e igreja a eles destinado. Naquele espaço, "casavam-se, tinham filhos, recebiam muita esmola e contavam com um cerrado bem denso onde podiam se esconder caso chegasse a onça - patrulha da Colônia Santa Marta de Goiânia" (Meza, 1997, p.156).

Desde 1939, a população da cidade de Jataí reclamava "[d]a invasão daquelas regiões por hanseanos [sic]", que vinham "corridos do Triângulo Mineiro", das cidades de Uberlândia, Tupaciguara e Avantiguara, onde o fortalecimento da campanha antileprótica levava os doentes a buscar o estado vizinho, atrasado no seu programa de implantação de instituições e órgãos isoladores (O problema..., 20 abr. 1939, p.1). Esses doentes foram se aglomerando em uma região da cidade onde, mais tarde, foi organizado e planejado um bairro denominado Vila Santa Maria ou Vila dos Hansenianos (ou ainda Comunidade Vicentina).

A ação foi iniciada na década de 1940 por missionários protestantes e continuada na década de 1960 pela Igreja católica. Os missionários James Watson e Nora Buyers, ${ }^{9}$ da Congregação Presbiteriana, organizaram o leprosário a partir de 1955, ajudados mais tarde por Margarida Pittman, e construíram uma igreja. Como naquela comunidade se mantinha a estrutura familiar dos doentes, a "igreja furada" foi edificada com tijolos vazados para facilitação da circulação do ar e diminuição do risco de contaminação dos sadios. A partir de 1958, o médico Joaquim Netto Martins assumiu o Dispensário de Doença de Pele da região. Ele indicava os enfermos que deviam ser encaminhados à Colônia Santa Marta para tratamento; todavia, para os doentes ali estabelecidos, o cuidado recebido na colônia era considerado desumano, o que os incentivava a fugir quando da iminência de ser apreendidos (Meza, 1997, p.154-158).

A população agia contraditoriamente em relação aos doentes. Por um lado, mobilizavase para a manutenção material, por outro, rechaçava-os da convivência, exigindo que se mantivessem minimamente afastados dos sadios. O memorialista Dorival Carvalho Melo (2002) comenta que, na década de 1960, um sanitarista local teria proposto deixar os doentes morrerem de inanição, o que solucionaria irrevogavelmente o problema. ${ }^{10}$

A necessidade de fortalecimento dos programas de assistência social aos familiares de leprosos é comentada por Abrahão Salomão, em 1949. Ele insiste na importância do papel do Estado, aconselhando a criação de órgãos oficiais de assistência para trabalhar em acordo com as sociedades de proteção aos lázaros. Pois,

internado o doente de lepra, inicia-se a tragédia de sua família que se vê imediatamente repudiada pela sociedade, estigmatizada pela doença, não encontrando trabalho pelo horror injustificado que inspira a todos. Os filhos são muitas vezes expulsos das escolas, e, quando isso não acontece, eles são objeto de repulsa e de incompreensão (Salomão, 1949, p.185).

A solução apresentada por esse médico era o desenvolvimento de ações por meio do Estado - autoridades locais e órgãos da administração pública -, para dar ocupação aos familiares dos leprosos; seja em organizações industriais, serviços públicos ou em empresas de transporte. Insistia ainda na necessidade de educação sanitária do povo para expor a irracionalidade da "fobia" relativa aos descendentes do doente (Salomão, 1949). 
A institucionalização dos filhos sadios de doentes internados em leprosários surge como solução para o problema social causado pelo afastamento dos pais de seus lares. Suas vidas nessas instituições tinham um caráter medicalizado e de associação direta com as ações advindas das políticas antilepróticas. A partir da década de 1950 inicia-se um questionamento relativamente a esse modelo. Quando a política de profilaxia da lepra entra em crise no Brasil e deixa entrever o enorme peso financeiro daquele modelo de saúde pública, essa carência se reflete também nas atividades de assistência aos familiares dos doentes, especialmente às crianças internadas em preventório. No entanto, diante das condições sociais das famílias e do cotidiano de dependência já estabelecido, tornava-se impossível simplesmente abortar o programa. Nesse momento o que se percebe é a contradição entre a carência de financiamento público, a dependência das ações filantrópicas e o nascimento da responsabilidade assistencial como um direito social que devia ser reconhecido.

\section{NOTAS}

${ }^{1}$ Nesse quadro de novas construções teóricas e arquitetônicas, temos os estudos desenvolvidos pela Comissão de Profilaxia da Lepra e a elaboração, por Adelardo Soares Cauby, do modelo das cidades-leprosários para isolamento.

${ }^{2}$ Neste trabalho tomaremos a divisão administrativa do estado de Goiás referente ao período estudado (1920-1962). Nesse período, a ilha do Bananal fazia parte do seu território e situava-se no espaço de fronteira com os estados do Pará e do Mato Grosso. É importante salientar que, na década de 1980, com a divisão do território goiano e a constituição de um novo estado (Tocantins), a ilha do Bananal passa a fazer parte desse novo estado da federação.

${ }^{3}$ A cidade, que havia deixado de ser capital do estado, não constava do projeto federal de construção de leprosários, tendo sido preterida por Jataí, embora o interesse daquela população se mostrasse há muito. A distribuição da verba entre as três instituições sediadas na cidade possuía, assim, um conteúdo bairrista.

${ }^{4}$ Segundo os estudos desenvolvidos com a positivação dos exames de Mitsuda, acreditava-se que os organismos tornavam-se imunes aos microrganismos causadores da lepra.

${ }^{5}$ A comissão técnica organizadora do regulamento foi composta por Ernani Agrícola, Heraclídes de Sousa Araújo, Nelson de Sousa Campos, Manoel Ferreira, Eunice Weaver e teve como relator Antônio Pereira Leal. Ele foi aprovado em 27 de janeiro de 1941.

${ }^{6}$ Os seis primeiros exames de Mitsuda (ocorridos nas seguintes datas: 28 jul. 1949; 27 ago. 1950; 27 out. 1950; 11 maio 1951; 14 set. 1951; 27 out. 1951) foram anteriores ao recebimento de três doses de BCG (em 31 dez. 1952; 11 mar. 1953 e 20 abr. 1953) e, para posterior avaliação da sua reação àquele tratamento preventivo, houve mais três exames de Mitsuda (25 maio 1953; 27 maio 1953 e 20 jun. 1953).

${ }^{7}$ Os seis exames de Mitsuda (realizados em 24 abr. 1950; 13 jun. 1950; 20 out. 1950; 11 maio 1951; 14 set. 1951 e 27 out. 1951) foram anteriores ao recebimento de três doses de BCG (31 dez. 1952; 11 mar. 1953 e 20 abr. 1953). Após a imunização com o BCG, a criança foi submetida a três exames de reação Mitsuda (25 maio 1953; 27 maio 1953 e 20 jun. 1953).

${ }^{8} \mathrm{O}$ “inferno dos tuberculosos" faz alusão a um estabelecimento médico provisório voltado aos atacados por essa enfermidade, construído na cidade de Goiânia.

${ }^{9}$ Esses missionários, de origem norte-americana, chegaram em Jataí em 1950, e, além de atuar na área da educação, coordenaram o processo de construção, na região já ocupada pelos doentes, do leprosário que foi depois repassado para a administração da Igreja católica local.

${ }^{10}$ Na década de 1960, com auxílio do padre Thiago (James Philip Menelli) à cidade e a construção da igreja São Sebastião na mesma localidade, iniciou-se um processo de planificação do bairro e de organização da comunidade hanseniana. 


\section{REFERÊNCIAS}

AGRÍCOLA, Ernani.

Lepra no Brasil Central. Revista Arquivos de Saúde Pública, ano 1, n.2, p.38-49. 1951.

ALMEIDA, Eliel Martins de.

O combate à lepra, 9. Correio Oficial, n.221, p.1. 29 out. 1938.

ALMEIDA, Eliel Martins de.

O problema da lepra: preventórios, 14. Correio

Oficial, n.213, p.4. 21 out. 1937.

ALMEIDA, Eliel Martins de.

O problema da lepra: preventórios, 15. Correio

Oficial, n.213, p.1. 16 out. 1937.

ALMEIDA, Eliel Martins de.

O problema da lepra no Brasil: a profilaxia urbana, 8. Correio Oficial, n.211, p.1. 24 jul. 1937.

ALVARENGA, Antonia Valtéria Melo.

Desenvolvimento e segregação: políticas de modernização e isolamento compulsório de famílias afetadas pela lepra no Piauí, 19301960. Tese (Doutorado em História) - Instituto de Ciências Humanas e Filosofia, Universidade Federal Fluminense, Niterói. 2011.

ANDRADE, Márcio Magalhães de. O princípio do mal: a ameaça leprosa no Rio de Janeiro colonial. Dissertação (Mestrado em História das Ciências e da Saúde) - Casa de Oswaldo Cruz, Fundação Oswaldo Cruz, Rio de Janeiro. 2005.

ARAÚJO, Heraclídes Cesar de Souza. A lepra e as organizações antileprosas do Brasil em 1936. Memórias do Instituto Oswaldo Cruz, v.32, n.1, p.154. 1937.

\section{ASSOCIAÇÃO..}

Associação Beneficente São Lázaro: Leprosário de Goiás. Convite. p.4. 6 jun. 1940.

AUTOS...

Autos do processo contra a construção do Leprosário de Goiás. Certidão. Coleção Administração da Cidade de Goiás (Arquivo da Fundação Cultural Frei Simão Dorvi, Goiás). 1927-1935.

BRAGA, Felisberto; NETO, Elias.

Discurso: edil aponta irregularidade no

Educandário Afrânio de Azevedo. Diário da Tarde, Goiânia. 15 maio 1959.

BRASIL.

Lei n.610/1949. Fixa normas para a profilaxia da lepra. Serviço Nacional de Lepra. 13 jan. 1949.

BRITO, Sebastião Mendonça de.

Dados históricos sobre a campanha contra a

lepra em Goiás. Revista Educação e Saúde, n.29-30, p.51-53. ago.-set. 1946.
CAIADO, Brasil de Ramos.

Serviço sanitário. Mensagem enviada ao congresso legislativo do estado de Goiás a 4 de junho de 1927, pelo presidente dr. Brasil de Ramos Caiado. Correio Oficial, n.1298, p.15. 1927.

CAMPOS, Nelson de Souza.

O BCG na profilaxia da lepra: revisão bibliográfica. Revista Brasileira de Leprologia, v.21, n.4, p.292-314. 1953.

\section{CARTA ENVIADA...}

Carta enviada pelas sras. Maria do Rosário Caldas Pinheiro (presidente) e Themis dos Reis Teixeira (tesoureira), do Educandário Afrânio de Azevedo, à Câmara Municipal. Edis x edis: Preventório Afrânio de Azevedo é um bom estabelecimento. Diário da Tarde, p.2. 18 maio 1959.

CIDADE DE GOIÁS.

Balancete do Hospital São Pedro de Alcântara. Coleção Hospital São Pedro de Alcântara (Arquivo da Fundação Cultural Frei Simão Dorvi, Goiás). 1940.

\section{CONCORRÊNCIA PÚBLICA...}

Concorrência pública: construção do preventório para filhos de lázaros de Goiás. Correio Oficial, n.228, p.4. 6 dez. 1941.

COSTA, Dilma Fátima Avellar Cabral da.

Entre ideias e ações: medicina, lepra e políticas públicas de saúde no Brasil (1894-1934). Tese (Doutorado em História) - Universidade Federal Fluminense, Niterói. 2007.

COSTA, Odorico.

A campanha contra a lepra em Goiás. Correio Oficial, n.232, p.1, 4.28 set. 1943.

CUNHA, Vívian da Silva.

O isolamento compulsório em questão: políticas de combate à lepra no Brasil (1920-1941). 2005. Dissertação (Mestrado em História das Ciências e da Saúde) - Casa de Oswaldo Cruz, Fiocruz, Rio de Janeiro. 2005.

CURI, Luciano Marcos.

Lepra e preventórios do Brasil: a educação a serviço do "bem". Evidência, ano 2, n.2, p.149179. 2006.

CURI, Luciano Marcos.

Defender os sãos e consolar os lázaros: lepra e isolamento no Brasil, 1935-1976. Dissertação (Mestrado em História) - Universidade Federal de Uberlândia, Uberlândia. 2002.

DANZELOT, Jacques.

A polícia das famílias. Rio de Janeiro: Graal. 1986. 
DECLARAÇÃO...

Declaração da Comissão de Vereadores. Edis x edis: Preventório Afrânio de Azevedo é um bom estabelecimento. Diário da Tarde, p.2. 18 maio 1959.

DECRETO-LEI...

Decreto-lei n.8.037, de 22 de outubro de 1943. Autoriza a doação de terrenos suburbanos à Sociedade de Assistência aos Lázaros e Defesa Contra a Lepra, para a constituição do Patrimônio do Preventório de Goiânia. Correio Oficial, n.233, p.2. 4 nov. 1943.

DELAPORTE, François.

Contagion et infection. In: Lecourt, Dominique. Dictionnaire de la pensée médicale. Paris: PUF. p.283-287. 2004.

DINIZ, Orestes.

Vulto da endemia de lepra no Brasil. Revista Arquivos de Saúde Pública, ano 1, n.2, p.50-65. 1951.

EDITAL...

Edital: Sociedade Goiana de Assistência aos Lázaros e Defesa Contra a Lepra. Correio Oficial, n.243, p.4. 20 set. 1947.

FEITOSA, João Marcos.

A influência evangélica na sociedade anapolina.

Dissertação (Mestrado em Ciências da Religião) Universidade Católica de Goiás, Goiânia. 2002.

FESTA...

Festa da caridade. Correio Oficial, n.233, p.1. 17 set. 1943.

FOUCAULT, Michel.

História da loucura na Idade Clássica. Trad. José Teixeira Coelho Netto. São Paulo: Perspectiva. 2004.

FOUCAULT, Michel.

Microfísica do poder. Rio de Janeiro: Graal. 1979.

GOIÁS.

Diretoria Geral dos Serviços Sanitários.

Regulamento de Saúde Pública, artigo 326, p.93. 1932.

GUIMARÃES, Celma Martins; CRUZ, Alaíde Ferreira da.

Preventório Afrânio de Azevedo de Goiânia: um estudo de assistência prestada aos filhos de hansenianos. Estudos Goiânia, v.29, n.5, p.14511742. 2002.

IBGE.

Instituto Brasileiro de Geografia e Estatística. Censo da Lepra. Número de internados em preventório em Goiás, Goiânia (Estatísticas do século XX, série Saúde; dados relativos aos anos de 1944 a 1956). CD-ROM. s.d.
INICIADA...

Iniciada promissoramente a Campanha Contra a Lepra. Correio Oficial, n.228, p.1. 29 nov. 1941.

INICIATIVA...

Iniciativa louvável. Correio Oficial, n.228, p.1. 27 nov. 1941.

LEI...

Lei n.4 de 4 de novembro de 1935. Correio Oficial, p.2. 10 nov. 1935 .

LIMA, Zilda Maria Menezes.

"Irmãs de sina": lembranças do Preventório Eunice Weaver em Maranguape, CE (1940-1970). In: Nascimento, Dilene Raimundo do; Marques, Vera Regina Beltrão (Org.). Hanseníase: a voz dos que sofreram o isolamento compulsório. Curitiba: EdUFPR. p.93-116. 2011.

MACIEL, Laurinda Rosa.

Em proveito dos sãos, perde o lázaro a liberdade: uma história das políticas públicas de combate à lepra no Brasil (1941-1962). Tese (Doutorado em História) - Universidade Federal Fluminense, Niterói. 2007.

MÃES HANSENIANAS...

Mães hansenianas agradecem a ajuda dada pelas mães sadias. Diário do Oeste, p.1. 23 jan. 1963.

MAURO BORGES...

Mauro Borges visitará Preventório. Diário Oficial, n.289, p.6. 11 set. 1962.

MELO, Dorival Carvalho.

Nos porões do passado: a descoberta de Jataí. Jataí: Sudográfica. 2002.

MEZA, Rúbia Marce de Moraes Ribeiro.

A hanseníase na construção da história de um povo. Tecnia, v.2, n.2. p.154-158. 1997.

MONTEIRO, Yara Nogueira.

Da maldição divina à exclusão social: um estudo da hanseníase em São Paulo. Tese (Doutorado em Ciências) - Universidade de São Paulo, São Paulo. 1995.

NATAL....

Natal dos filhos de lázaros. Correio Oficial, n.232, p.1. 3 dez. 1943.

NESTA CAPITAL..

Nesta capital a presidente da Federação da Defesa Contra a Lepra. Correio Oficial, n.232, p.1. 16 jun. 1943.

O COMBATE...

O combate à lepra em Goiás. Correio Oficial, n.221, p.1. 27 dez. 1938.

O EDUCANDÁRIO...

O Educandário Afrânio Azevedo. Revista Oeste, ano 3, n.12, p.463. (Edição fac-similar). 1944. 
OFÍCIO...

Ofício da Diretoria do Serviço Sanitário do Estado de Goiás (Laudelino Gomes) para a Diretoria do Interior. Caixa 807; documentos avulsos. (Arquivo Histórico do Estado de Goiás, Goiânia). 5 abr. 1932.

OFÍCIO...

Ofício do interno da Colônia Santa Marta (JRF) a André Mundim, prefeito de Goiás. Coleção Administração da Cidade de Goiás. (Arquivo da Fundação Cultural Frei Simão Dorvi, Goiás). 14 set. 1953.

OLINTO, Beatriz Anselmo.

Pontes e muralhas: diferenças, lepra e tragédia (Paraná, início do século XX). Tese (Doutorado em História) - Universidade Federal de Santa Catarina, Florianópolis. 2002.

O PRIMEIRO CONTATO...

O primeiro contato do presidente Getúlio Vargas com o povo goiano. Correio Oficial, n.226, p.1-2. 8 ago. 1940.

O PROBLEMA...

O problema da assistência aos lázaros. Correio Oficial, n.223, p.1. 29 out. 1939.

O PROBLEMA...

O problema da lepra no sudoeste goiano. Correio Oficial, n.223, p.1. 20 abr. 1939.

OPROMOLLA, Paula Araújo.

Informação em saúde: a trajetória da hanseníase no Estado de São Paulo, 1800-2005. Tese (Doutorado em Epidemiologia) - Faculdade de Saúde Pública, Universidade de São Paulo. 2007.

PARECER...

Parecer da Comissão de Análise para Construção do Leprosário da Cidade de Goiás. Caixa 864; documentos avulsos (Arquivo Histórico do Estado de Goiás, Goiânia). 1935.

PEREIRA, Antônio Carlos.

Métodos de profilaxia da lepra. Arquivos Mineiros de Leprologia, ano 20, n.1, p.9. 1960.

RELATÓRIO...

Relatório da Inspectoria de Higiene Pública do Estado de Goiás. Arquivo Histórico Estadual de Goiás. Caixa 401, pacote 1. Goiânia. jan. 1890.
REGULAMENTO...

Regulamento dos preventórios para filhos de lázaros, instalados no Brasil. Correio Oficial, p.7-8. 1 mar. 1944.

RESUMO....

Resumo da Ata de Sessão de Fundação da

Sociedade de Assistência aos Lázaros e Defesa

Contra a Lepra de Goiânia. Correio Oficial, n.228, p.2-3. 20 dez. 1941.

REZENDE, Valério T. de.

Assistência social à família dos hansenianos, alienados e sentenciados. Arquivos Mineiros de Leprologia, ano 1, n.1, p.29-32. 1941.

SALOMÃO, Abrahão.

Serviços oficiais de assistência social às famílias de hansenianos internados. Arquivos Mineiros de Leprologia, ano 9, n.3, p.185. 1949.

SANGLARD, Gisele Porto.

Entre os salões e o laboratório: filantropia, mecenato e práticas científicas, Rio de Janeiro, 1920-1940. Tese (Doutorado em História das Ciências e da Saúde) - Casa de Oswaldo Cruz, Fiocruz, Rio de Janeiro. 2005.

SANTOS, Luiz Antonio de Castro; FARIA, Lina; MENEZES, Ricardo Fernandes de.

Contrapontos da história da hanseníase no Brasil: cenários de estigma e confinamento. Revista Brasileira de Estudos Populacionais, v.25, n.1, p.167-190. 2008.

SANTOS, Vicente Saul Moreira dos. Filantropia, poder público e combate à lepra (1920-1945). História, Ciências, SaúdeManguinhos, v.18, supl.1, p.253-274. 2011.

SANTOS, Vicente Saul Moreira dos. Entidades filantrópicas e políticas públicas no combate à lepra: Ministério Gustavo Capanema, 1934-1945. Dissertação (Mestrado em História das Ciências e da Saúde) - Casa de Oswaldo Cruz, Fundação Oswaldo Cruz, Rio de Janeiro. 2006.

SILVA FILHO, Pedro Celestino da.

A Escola Nova sob tríplice aspecto da educação: física, sanitária e moral. Revista de Educação, ano 1, n.2, p.44-50. 1937.

TRECHO...

Trecho da "Carta da Presidência", n.25. Correio Oficial, n.232, p.7. 9 jun. 1943.

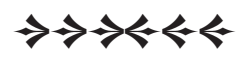

